Acoustics for Engineers 
Macmillan titles of interest to mechanical engineers

Turner

Simonson

Hull and John

Stone

Stone

Hall

Goodger

John

John

Drabble

Boxer

Boxer
Instrumentation for Engineers

Engineering Heat Transfer, 2nd edition

Non-Destructive Testing

Introduction to Internal Combustion Engines

Motor Vehicle Fuel Economy

Polymer Materials, 2nd edition

Principles of Engineering Thermodynamics, 2nd edition

Introduction to Engineering Materials, 2nd edition

Work Out Engineering Materials

Work Out Dynamics

Work Out Thermodynamics

Work Out Fluid Mechanics

Foundations of Engineering series

Drabble Dynamics

Hulse and Cain $\quad$ Structural Mechanics

Powell Electromagnetism

Silvester $\quad$ Electric Circuits 


\title{
Acoustics for Engineers
}

\author{
J. D. Turner and A. J. Pretlove
}

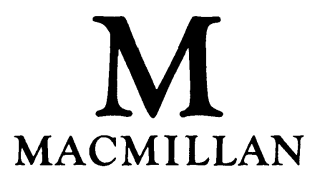


All rights reserved. No reproduction, copy or transmission of this publication may be made without written permission.

No paragraph of this publication may be reproduced, copied or transmitted save with written permission or in accordance with the provisions of the Copyright, Designs and Patents Act 1988 or under the terms of any licence permitting limited copying issued by the Copyright Licensing Agency, 33-4 Alfred Place, London WC1E 7DP.

Any person who does any unauthorised act in relation to this publication may be liable to criminal prosecution and civil claims for damages.

First edition 1991

Published by

MACMILLAN EDUCATION LTD

Houndmills, Basingstoke, Hampshire RG21 2XS

and London

Companies and representatives

throughout the world

British Library Cataloguing in Publication Data

Turner, J. D. (John David), 1955-

Acoustics for engineers.

1. Acoustic engineering

I. Title II. Pretlove, A. J.

620.2

ISBN 978-0-333-52143-4

ISBN 978-1-349-21267-5 (eBook)

DOI 10.1007/978-1-349-21267-5 
To our children,

$$
\text { Jack, }
$$

Gareth,

John,

Steve,

and James,

who, very early in their lives,

taught us the importance of noise control. 


\section{Contents}

Preface $\quad$ xi

Acknowledgements $\quad \mathrm{xv}$

1. Basic concepts of noise and vibration 1

1.1 The general nature of sound 2

1.1.1 Derivation of the one-dimensional wave equation 4

1.1.2 Sound in air 8

1.1.3 Relationship between pressure and velocity: the energy in a sound wave 10

$\begin{array}{lll}1.1 .4 & \text { Electric circuit analogy } & 12\end{array}$

$\begin{array}{lll}\text { 1.1.5 The decibel scale } & 14\end{array}$

$\begin{array}{lll}\text { 1.1.6 Adding decibels } & 17\end{array}$

1.2 Basic vibration theory for single degree of freedom systems 19

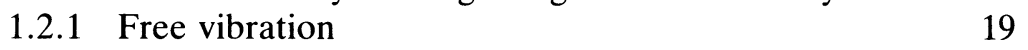

1.2.2 Forced vibration 22

1.2.3 Control of forced vibration 24

1.2.4 Vibration isolation 25

1.2.5 Continuous systems and their single degree
of freedom equivalents

References 31

2. The human effects of noise: criteria and units 32

2.1 Introduction $\quad 32$

2.2 The ear 33

2.3 Audiometry 36

2.4 Loudness 36 
2.5 Weighting functions 39

2.6 Noise-related hearing loss 40

2.7 Noise exposure limits and noise units 41

2.8 Noise criterion (NC) and noise rating (NR) curves 41

$2.9 L_{10}$ and $L_{90}$

2.10 Equivalent continuous sound level $\left(\boldsymbol{L}_{\mathrm{eq}} \mathrm{dBA}\right)$

2.11 Community noise annoyance criteria 44

2.12 Aircraft noise measurements: units and criteria 47

2.13 Hearing damage risk criteria 48

2.14 Masking $\quad 50$

2.15 Speech interference criteria $\quad 52$

References $\quad 54$

3. Sound in three dimensions 55

3.1 Introduction 55

3.2 Spherical waves $\quad 55$

3.3 Directionality 64

3.4 Membrane microphones: a more quantitative theory 66

$\begin{array}{lll}3.5 & \text { Directivity } & 70\end{array}$

3.6 Screens 71

3.7 Sound in the open air 75

$\begin{array}{lll}3.8 & \text { Summary } & 77\end{array}$

4. Analysis of acoustic and vibration signals 78

4.1 Introduction 78

4.2 Fourier series 83

4.3 Even and odd functions $\quad 87$

4.4 The complex form of the series 89

4.5 The Fourier Transform 90

4.6 Summary 94

References/further reading $\quad 95$

5. Digital methods of spectrum analysis 96

5.1 Introduction 96

5.2 The digital Fourier Transform and the FFT 96

5.3 Practical use of the FFT for spectral analysis 98

5.4 Aliasing and Shannon's Sampling Theorem 100

$\begin{array}{ll}5.5 \text { Windowing } & 103\end{array}$

5.6 Choice of window 111

5.7 Glossary of FFT analyser terminology 114

References/further reading $\quad 115$

6. Acoustic instrumentation 116

6.1 Introduction 116 
$\begin{array}{llr}6.2 & \text { Microphones } & 119\end{array}$

$\begin{array}{ll}\text { 6.3 Measurements in an airstream } & 123\end{array}$

$\begin{array}{ll}6.4 \text { Hydrophones } & 125\end{array}$

$\begin{array}{ll}\text { 6.5 Microphone and hydrophone calibration } & 125\end{array}$

$\begin{array}{ll}\text { 6.6 Sound intensity measurement } & 129\end{array}$

6.7 Amplifiers and weighting filters 134

$\begin{array}{lll}6.8 & \text { Signal storage equipment } & 136\end{array}$

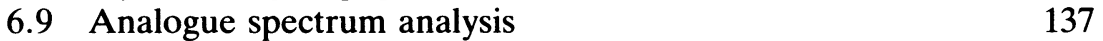

$\begin{array}{ll}\text { References } & 141\end{array}$

7. Reflection and transmission: sound in confined spaces 142

$\begin{array}{lll}7.1 & \text { Introduction } & 142\end{array}$

7.2 Reflection of plane waves at a boundary 143

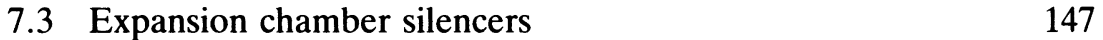

$\begin{array}{lll}7.4 & \text { Dissipative silencers } & 150\end{array}$

7.5 Acoustic absorption at surfaces in rooms 151

$\begin{array}{lll}\text { 7.6 Sound in enclosed spaces: room acoustics } & 155\end{array}$

$\begin{array}{lll}7.7 & \text { RT calculations in problem solving } & 159\end{array}$

7.8 Case study: acoustic treatment of Reading central swimming baths

7.9 Estimating the SPL for a room of known RT, for a

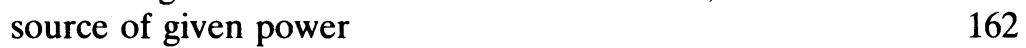

$\begin{array}{ll}7.10 \text { Sound transmission } & 166\end{array}$

$\begin{array}{ll}\text { References } & 173\end{array}$

$\begin{array}{lr}\text { 8. Noise control } & 174\end{array}$

$\begin{array}{lll}8.1 \text { Introduction } & 174\end{array}$

$\begin{array}{ll}8.2 \text { Noise-conscious design } & 175\end{array}$

$\begin{array}{lll}8.3 & \text { Existing noise problems } & 175\end{array}$

$\begin{array}{lll}8.4 & \text { Acoustic systems } & 176\end{array}$

8.5 Analysis using the series-parallel method 180

8.6 Case study of the noise from a wood fibre mill 182

8.7 Cost analysis of noise control measures 184

$\begin{array}{ll}\text { Reference } & 187\end{array}$

$\begin{array}{lr}\text { Index } & 188\end{array}$ 


\section{Preface}

Sound is a phenomenon which all human beings live with from birth, and perhaps even before. It is a familiar medium of communication with our fellow man and it includes speech and the pleasures of music. Hearing is one of our primary senses, at once vitally valuable to our development and of infinitely varied interest. Sound can also be an irritating nuisance. All of this is taken for granted by most people. Because it is so familiar, relatively few will question how it works. Indeed, the basic physics of sound was not understood at all two hundred years ago. The pioneering work of early physicists such as Helmholtz (1821-1894) and Lord Rayleigh (1842-1919) defined sound as a form of wave motion and the wave theory explained various well-known phenomena such as diffraction (hearing a sound round a corner) and echoes (reflected sound with time delay). Once sound was recognised as a form of wave motion it could be brought into the family of wave phenomena and analogies could then be made with light, electromagnetic radiation and so forth, to the mutual benefit of all. An understanding of the physics of sound is particularly essential to the practising engineer whose task is often to design noise control devices for the factory, the office and at home.

Noise can be just as damaging as any other form of pollution. It may cause irritation or annoyance, and can be a danger to health. For these reasons, legal limits on the exposure to and emission of noise exist in most countries. As well as these health and safety aspects of noise, our acoustic environment is under constant threat from the increase in use and power of vehicles and machinery of all sorts. The benefits of a quiet environment, which was once accepted as the norm, are increasingly appreciated. The preference therefore is for quieter products whenever possible, and this is often reflected by the selling advantage the quiet product has over its noisy competitor. 
Noise measurement is an important weapon in the armoury of the engineer concerned with diagnosing or monitoring the condition of machinery. The wheel-tapper who used to be employed on railways is a familiar example. We all know that faulty machines often emit unusual sounds prior to failure. The sounds made by machinery in normal use can be monitored to give advance warning of maintenance requirements. Measurement is therefore a subject of fundamental importance to the noise control engineer. Without it, there is no means of quantifying the extent of a noise problem. A modern measurement system is considerably different from its counterpart of even ten years ago. The only component which is the same is the microphone itself. The rest of the system has, with the advent of the ubiquitous microprocessor or microcomputer, gone digital. In acoustical analysis, digital signal processing is now of paramount importance because of its power, accuracy and speed. For this reason, a considerable proportion of this book is devoted to the fundamental principles of measurement and analysis. This includes not only Fourier analysis but also other useful aspects of signal processing.

Noise costs money. Processes which are inevitably noisy will require expenditure on noise insulation. Excessive noise levels can lead to annoyance or to a loss of concentration, and productivity may fall. The control of noise is therefore important not only to prevent hearing damage and maintain a pleasant environment, but also from the economic point of view. A novel strategy for tackling noise control problems is given in the last chapter of this book. The task of diagnosing and correcting noise problems in the most effective manner is one which, in the past, has received little attention in a formal way. It is hoped that this will provide the reader with an accurate method for defining the best medicine to be prescribed for the noisy patient.

The book is therefore unusual in integrating modern measurement techniques with fundamentals of applied acoustics and the determination of the most effective treatment of noise problems. By this means an up-to-date statement of the basics of noise and noise control is presented. The book aims to describe the basic theory and its practical applications in an easily digestible way with plenty of examples drawn from a wide variety of backgrounds.

Apart from being of general interest, the book is intended to be of value to students on courses of higher education and perhaps particularly to student engineers who, in their later professional lives, will often be faced with problems associated with noise. Many engineering degree courses now recognise the importance of noise control to the practising engineer and this book is designed to fulfil a need for a text which covers, in reasonably concise and up-to-date form, the major aspects of the subject.

The authors acknowledge the constructive comment and informed criticism of their many interested colleagues at Reading, Southampton and 
elsewhere in the preparation of this book. Particular thanks are due to Martyn Hill, who patiently read the manuscript and made many helpful comments. 


\section{Acknowledgements}

The authors wish to thank Professors M. T. Thew of Southampton University and A. G. Atkins of Reading University, for their encouragement of the work on which this book is based. We would also like to acknowledge the assistance provided by Mr M. Hill and Professor F. Fahy.

The index was produced with the aid of an extremely efficient piece of software called MACREX. The authors were lent a copy of MACREX by its creators, and would like to record their gratitude.

Permission for the reproduction of a number of figures and tables is acknowledged from Bruel and Kjaer Ltd. These are indicated in the text.

Every effort has been made to trace all copyright holders but if any have been inadvertently overlooked the publishers will be pleased to make the necessary arrangement at the first opportunity. 